\title{
The Interplay between Protein L-Isoaspartyl Methyltransferase Activity and Insulin-Like Signaling to Extend Lifespan in Caenorhabditis elegans
}

\author{
Shilpi Khare ${ }^{1 *}$, Carole L. Linster ${ }^{1,3 *}$, Steven G. Clarke ${ }^{1,2 *}$ \\ 1 Department of Chemistry and Biochemistry, University of California-Los Angeles, Los Angeles, California, United States of America, 2 Molecular Biology Institute, \\ University of California-Los Angeles, Los Angeles, California, United States of America, 3 Laboratory of Physiological Chemistry, de Duve Institute and Université catholique \\ de Louvain, Brussels, Belgium
}

\begin{abstract}
The protein L-isoaspartyl-O-methyltransferase functions to initiate the repair of isomerized aspartyl and asparaginyl residues that spontaneously accumulate with age in a variety of organisms. Caenorhabditis elegans nematodes lacking the $\mathrm{pcm}-1$ gene encoding this enzyme display a normal lifespan and phenotype under standard laboratory growth conditions. However, significant defects in development, egg laying, dauer survival, and autophagy have been observed in $\mathrm{pcm}-1$ mutant nematodes when deprived of food and when exposed to oxidative stress. Interestingly, overexpression of this repair enzyme in both Drosophila and C. elegans extends adult lifespan under thermal stress. In this work, we show the involvement of the insulin/insulin-like growth factor-1 signaling (IIS) pathway in PCM-1-dependent lifespan extension in C. elegans. We demonstrate that reducing the levels of the DAF-16 downstream transcriptional effector of the IIS pathway by RNA interference reduces the lifespan extension resulting from PCM-1 overexpression. Using quantitative real-time PCR analysis, we show the up-regulation of DAF-16-dependent stress response genes in the PCM-1 overexpressor animals compared to wild-type and $\mathrm{pcm}-1$ mutant nematodes under mild thermal stress conditions. Additionally, similar to other long-lived C. elegans mutants in the IIS pathway, including daf-2 and age-1 mutants, PCM-1 overexpressor adult animals display increased resistance to severe thermal stress, whereas $\mathrm{pcm}-1$ mutant animals survive less long under these conditions. Although we observe a higher accumulation of damaged proteins in pcm-1 mutant nematodes, the basal level of isoaspartyl residues detected in wild-type animals was not reduced by PCM-1 overexpression. Our results support a signaling role for the protein L-isoaspartyl methyltransferase in lifespan extension that involves the IIS pathway, but that may be independent of its function in overall protein repair.
\end{abstract}

Citation: Khare S, Linster CL, Clarke SG (2011) The Interplay between Protein L-Isoaspartyl Methyltransferase Activity and Insulin-Like Signaling to Extend Lifespan in Caenorhabditis elegans. PLoS ONE 6(6): e20850. doi:10.1371/journal.pone.0020850

Editor: Matt Kaeberlein, University of Washington, United States of America

Received January 18, 2011; Accepted May 11, 2011; Published June 13, 2011

Copyright: (c) 2011 Khare et al. This is an open-access article distributed under the terms of the Creative Commons Attribution License, which permits unrestricted use, distribution, and reproduction in any medium, provided the original author and source are credited.

Funding: This work was supported by NIH Grant GM026020 and AG032303 and an Ellison Medical Foundation Senior Scholar in Aging Award. CLL is supported by the Fonds de le Recherche Scientifique (FNRS) and by the European Union Seventh Framework Programme (FP7/2007-2013) under grant agreement 276814. The funders had no role in study design, data collection and analysis, decision to publish, or preparation of the manuscript.

Competing Interests: The authors have declared that no competing interests exist.

*E-mail: clarke@mbi.ucla.edu (SGC); skhare@chem.ucla.edu (SK); carole.linster@uclouvain.be (CLL)

\section{Introduction}

A master regulator of aging in the nematode Caenorhabditis elegans is the insulin/insulin-like growth factor-1 signaling (IIS) pathway. The IIS pathway is conserved in other organisms, including Drosophila melanogaster and mammals [1]. Activation of the DAF-2 insulin-like receptor in C. elegans triggers the successive phosphorylation and activation of several kinases including AGE-1 (Class 1A phosphatidylinositol-3-kinase) and AKT (protein kinase B); the activated AKT kinase can subsequently phosphorylate the FoxO transcription factor DAF-16, excluding it from the nucleus and thereby rendering it inactive [2,3]. However, when this kinase cascade of phosphorylation events is deactivated, the DAF-16 transcription factor enters the nucleus, leading to the enhanced expression of genes involved in longevity, dauer formation, and stress resistance [2,3]. C. elegans mutants lacking a functional insulin-like receptor or PI3-kinase (daf-2 and age-1 mutants, respectively), display lifespan extensions spanning two-fold to ten-fold and show enhanced stress resistance [4-6]. The long-lived phenotype for the daf-2 pathway mutants is abolished upon additional mutation of the DAF-16 transcription factor $[5,7,8]$.

Another protein implicated in C. elegans longevity is the protein L-isoaspartyl (D-aspartyl)-O-methyltransferase (PCM-1), the product of the $p c m-1$ gene [9]. Known primarily for its protein repair role in higher organisms, this highly conserved enzyme specifically recognizes damaged aspartyl and asparaginyl residues that accumulate with age [10]. Following the spontaneous deamidation and/or isomerization of these residues, protein backbones become kinked. The repair enzyme methylates the $\alpha$-carboxyl group of isoaspartyl residues, thereby facilitating "unkinking" of the backbone and conversion of the isomerized residues back to normal L-aspartyl residues [10]. E. coli lacking the isoaspartyl methyltransferase gene display increased susceptibility to various environmental stresses [11]. Knockout mice in the corresponding Pcmt1 gene accumulate altered proteins, show growth retardation, and are subject to premature death from fatal seizures at an average age of 42 days [12]. In plants, absence of the repair methyltransferase has been shown to be involved in decreased seed longevity 
and germination vigor in Arabidopsis thaliana [13]. On the contrary, overexpression of the methyltransferase in E. coli results in increased survival under heat shock [14] and oxidative stress [15] and extended lifespan under thermal stress in D. melanogaster [16] and C. elegans [17].

Further characterization of this repair enzyme has revealed interplay between PCMT and major intracellular signaling pathways, including the IIS pathway and the mitogen-activated protein kinase (MAPK) pathway. For example, Pcmt1 knockout mice showed activation of the IIS signaling pathway as evidenced by increased phosphorylation of kinases including AKT, glycogen synthase kinase-3 beta (GSK-3 $\beta$ ), and PDK-1 [18]. In relation to the MAPK pathway, PCMT1-knockdown human cells stimulated with EGF (epidermal growth factor) showed increased phosphorylation of MAPK pathway components, including Raf-1, MEK, and ERK1/2 [19,20]. Additionally, Doyle and colleagues found that the absence of PCMT1 in mammalian lymph node cells causes T-cell hyperproliferation and increased phosphorylation of MAPK pathway components MEK1/2, ERK1/2, and RSK1 in response to CD3 receptor stimulation [21]. In contrast, enhanced PCMT1 expression induced by both valproic acid and lithium was accompanied by inactivation of GSK-3 $\beta$ in astrocytoma and neuroblastoma cells [22,23]. These findings illustrate that, in addition to protein repair, PGMT1 might be directly or indirectly involved in the regulation of the IIS pathway and/or the MAPK pathway in mammalian systems.

As opposed to mice, effects of a deficiency in the protein Lisoaspartyl-O-methyltransferase resulting from mutations in the pcm-1 gene in C. elegans become apparent only under certain stress conditions. In control conditions, $p c m-1$ mutants display a similar lifespan and brood size when compared to wild-type (N2) animals [24]. Under starvation conditions, $p c m-1$ mutants display defects in dauer formation and survival as well as L1 larvae survival [17,25]. During dauer formation, $p c m-1$ mutants display reduced levels of autophagy, indicative of enhanced insulin/TOR signaling in the absence of PCM-1 [25]. Furthermore, under oxidative stress conditions, we have recently shown that $p c m-1$ mutants display defects in egg laying as well as delayed larval development [26]. An additional mutation in the $d a f-2$ gene in the $p c m-1$ mutants restored a normal dauer lifespan [17] and recovered stress defects in larval development and egg laying [26], indicating an epistatic relationship between genes of the IIS pathway and the gene encoding the isoaspartyl methyltransferase.

Given the normal adult lifespan of pcm-1 mutant C. elegans, it was a surprise to find that PCM-1 overexpression extends adult lifespan two-fold compared to wild-type nematodes under mild thermal stress [17]. As it was previously shown that the lifespan extension of long-lived IIS pathway mutants is DAF-16-dependent, this work is focused on determining whether the prolonged lifespan of PCM-1 overexpressor animals also involves the transcriptional activity of DAF-16. Furthermore, the importance of the protein repair function of PCM-1 in this context has been addressed.

\section{Methods}

\section{Worm strains and procedures}

Standard procedures used to maintain C. elegans strains were adapted from Sulston and Hodgkin [27]. The N2 strain was obtained from the Caenorhabditis Genetics Center (St. Paul, MN). Two transgenic strains (PL51 and PL54) along with the pcm-1 (qa201) mutant strain were used for all experimental procedures [17]. Strain PL51 is a non-integrated strain that was created by injection of a plasmid expressing the $p \mathrm{~cm}^{-1}$ gene under its endogenous promoter into a pcm-1 mutant background. Three to seven-fold higher isoaspartyl methyltransferase activities were measured in transgenic PL51 worm extracts compared to wildtype N2 extracts prepared from animals grown in liquid culture [26]. Strain PL54 contains a similar plasmid (also in a pcm-1 mutant background) to the PL51 strain except that it encodes a PCM-1 protein with two mutated residues in the enzyme's AdoMet cofactor binding site $(G 88 \mathrm{~V}$ and $G 90 \mathrm{~V})$. Extracts prepared from PL54 nematodes did not demonstrate any methyltransferase activity [26]. The pcm-1 (qa201) mutant lacks exons 2-5 of the pcm1 gene [24] and alternative exon 1 from the partially overlapping C10F3.4/mcp-1 gene [26]. This allele was backcrossed eight times into an N2 background [17] to obtain the pcm-1 (qa201) strain, which also totally lacks methyltransferase activity. Protein Lisoaspartyl $O$-methyltransferase activity was measured again in each of the strains used in this study and values are provided in Table 1. The integrated DAF-16::GFP roller strain 17356 was used to test daf-16 RNAi efficacy and to monitor subcellular DAF16 localization under various conditions. This strain was kindly given to us by Dr. Brian Head (UCLA Department of Biological Chemistry). In the absence of daf-16 RNAi, we confirmed expression of the GFP-tagged DAF-16 protein in most cell types (including the hypodermis, neurons, intestine, and gonad) except the pharynx in the 17356 strain [28]. With daf-16 RNAi, we observed a loss of fluorescence in all the daf-16 expressing regions except for neurons. The efficiency of $p c m-1$ RNAi was tested with the $x t E x 104$ (UZ122) strain expressing a PCM-1::GFP fusion protein [25]. In the absence of pcm-1 RNAi, we confirmed PCM-1 expression (body wall, reproductive tissues, and neurons) as initially reported by Gomez et al. [25] and observed a decrease in fluorescence (except in neurons) following pcm-1 RNAi treatment in the $U Z 122$ strain. All strains were kept at $20^{\circ} \mathrm{C}$ or $25^{\circ} \mathrm{C}$ on nematode growth medium plates streaked with $E$. coli OP50 (NGM + OP50) [27].

\section{Lifespan analysis and RNAi}

The protocol used to complete the lifespan studies was adapted from Sutphin and Kaeberlein [29]. First, eggs from three strains (N2, PL51, and PL54) were collected following hypochlorite treatment of gravid adults and were transferred to NGM + OP50 plates. Following an approximately $48 \mathrm{~h}$ incubation at $20^{\circ} \mathrm{C}, \mathrm{L} 4$

Table 1. PCM-1 activity measurements in various C. elegans strains.

\begin{tabular}{ll}
\hline Strain & Methyl Groups Transferred (pmol/min/mg protein) \\
\hline N2 & $0.60 \pm 0.04$ \\
$p c m-1$ (qa201) & $0.01 \pm 0.03$ \\
$P L 51$ & $1.97 \pm 0.26$ \\
$P L 54$ & $-0.10 \pm 0.01$ \\
\hline
\end{tabular}

Nematode protein extracts were prepared from liquid culture and analyzed for PCM-1 methyltransferase activity as described by Kagan et al. (1997). Protein extracts were incubated with the methyl-accepting peptide substrate KASAisoD-LAKY $(100 \mu \mathrm{M})$ and $20 \mu \mathrm{M}\left[{ }^{14} \mathrm{C}\right]$-AdoMet at $30^{\circ} \mathrm{C}$ for $2 \mathrm{~h}$. Control incubations were conducted as above except that KASA-isoD-LAKY was not added to the reaction. Protein L-Isoaspartyl $O$-methyltransferase activity levels are given as the amount of methyl groups transferred after correction for the background levels measured in the absence of KASA-isoD-LAKY for the various C. elegans strains used in the lifespan analyses, thermotolerance assays, RTqPCR analyses, and isoaspartyl quantifications performed in this study. The results shown are means $( \pm S D)$ of two separate activity measurements conducted with one set of lysates.

doi:10.1371/journal.pone.0020850.t001 
larvae from each strain were transferred to NGM plates containing isopropyl $\beta$-D-1-thiogalactopyranoside at $1 \mathrm{mM}(p \mathrm{~cm}-1 \mathrm{RNAi})$ or $2 \mathrm{mM}$ (daf-16 RNAi) (IPTG; Anatrace, Inc. \#I-1003), $0.025 \mathrm{mg} /$ $\mathrm{ml}$ carbenicillin sodium salt (CB; Sigma \#C-1389), and $45 \mu \mathrm{M} 5-$ fluorodeoxyuridine (FUDR; Sigma \#46875) and streaked with RNAi-expressing bacteria (NGM + IPTG + CB + FUDR + RNAi). Following transfer (day 0), lifespan plates were incubated at $25^{\circ} \mathrm{C}$ until final scoring for survival was completed (survival was scored every other day until all animals were dead). Animals were considered dead when no signs of viability (motility, pharyngeal pumping, and response to platinum wire prodding) were detec. Lifespan experiments were repeated three times. Averages of mean and maximum survival were determined and examined for statistical significance using the ANOVA test for significance.

The RNAi bacteria (either scrambled control or daf-16 (I-5m24)) were obtained from the Ahringer library [30] kindly provided by Dr. Brian Head at the UCLA Department of Biological Chemistry. The pcm-1 RNAi feeding clone, derived from the $C$. elegans ORFeome Library v1.1 [31], was obtained from Open Biosystems (Huntsville, AL). Several clones were derived from the original bacterial stock; the clones \#2 and \#3 used in this study are lacking exon 3 or part of exon 2 of the $p c m-1$ (C10F3.5a) open reading frame, respectively. The identity of the RNAi clones was verified by sequencing using the sjj_R13H8.1 primers (listed on www.wormbase.org as sjj_R13H8.1_f: AGTACAGCAATTCGCAAATGAAA and sjj_R13H8.1_b: ATTGGATTTCGAAGfAAGTGGAT) for the daf-16 gene and the pL4440-dest-RNAi universal primers (For: GTTTTCGCAGTCACGACGTT, Rev: TGGATAACGGTATTACGGCG) for the $p c m-1$ gene. For lifespan experiments in C. elegans, individual RNAi bacterial colonies were grown in $\mathrm{LB}+50 \mu \mathrm{g} / \mathrm{mL}$ ampicillin for $7 \mathrm{~h}$ at $37^{\circ} \mathrm{C}$; bacteria were then seeded onto NGM + IPTG + CB + FUDR plates and allowed to grow for $72 \mathrm{~h}$ before L4 larvae transfer.

\section{Thermotolerance assays}

The protocol developed for this assay was adapted from Lithgow et al. [32], except that day 1 adult animals were tested at $37^{\circ} \mathrm{C}$ instead of $35^{\circ} \mathrm{C}$. L4 larvae from each strain were transferred (20-30 animals per trial) to NGM + OP50 plates and were placed at $20^{\circ} \mathrm{C}$ overnight. The next morning, plates were transferred to $37^{\circ} \mathrm{C}$ and, at the inffdicated times, nematodes were scored for viability (motility, pharyngeal pumping, and response to platinum wire prodding). Animals were considered dead when no signs of viability were detectable. The assay was repeated in triplicate and significance of survival time points was determined using the ANOVA test for significance.

\section{Microscopy Assays}

To monitor the subcellular localization of DAF-16 under various experimental conditions, the T7356 strain was used. For the microscopy assays at $25^{\circ} \mathrm{C}$, the progeny of RNAi-fed $17356 \mathrm{~L} 4$ larvae were grown at $25^{\circ} \mathrm{C}$ until adulthood in both control and pcm-1 RNAi conditions and were scored for DAF-16 localization as done previously by Henderson and Johnson [28]. For the microscopy assays at $37^{\circ} \mathrm{C}$, the progeny of RNAi-fed $17356 \mathrm{~L} 4$ larvae were grown in the same manner, except that animals were kept at $20^{\circ} \mathrm{C}$. At day 1 of adulthood, the control RNAi-treated and pcm-1 RNAi-treated nematodes were incubated at $37^{\circ} \mathrm{C}$ for two hours and DAF-16 subcellular localization was determined [28].

\section{Reverse transcription and quantitative real-time PCR}

RNA extraction and reverse transcription. For all four stains tested (N2, PL51, PL54, pcm-1 (qa201)), gravid adults were treated for $3 \mathrm{~min}$ in a final concentration of $1.9 \%$ sodium hypochlorite and $0.3 \mathrm{M} \mathrm{NaOH}$. After five washes with M9 media, eggs were collected and starved overnight in M9 media to obtain synchronized L1 larvae. The L1 larvae were then transferred to $\mathrm{NGM}+\mathrm{OP} 50$ plates and were incubated at $25^{\circ} \mathrm{C}$ for $48 \mathrm{~h}$ until nematodes had reached day 1 of adulthood. Day 1 adults were collected in M9 media ( $n=200$, triplicate samples for each strain) and stored at $-80^{\circ} \mathrm{C}$. For total RNA extraction, animals were homogenized in $1 \mathrm{~mL}$ TRI Reagent ${ }^{\circledR}$ (Molecular Research Center, \#TR-118) with $1 \% \quad \beta$-mercaptoethanol (BioUltra, Sigma, \#63689) using a Polytron PT2000 homogenizer with a $7 \mathrm{~mm}$ generator. Phase separation of RNA from DNA and proteins was completed using bromochloropropane (Molecular Research Center, \#BP-151). RNA was DNAse-treated and further purified using the RNeasy Fibrous Tissue Mini Kit (Qiagen; Cat \# 74704). Following quantitation of RNA by measuring the absorbance at $260 \mathrm{~nm}$ using a NanoDrop spectrophotometer (the yield was generally about $4 \mu \mathrm{g}$ RNA per 200 animals) and verification of absence of protein contamination by $260 / 280 \mathrm{~nm}$ ratio determination (between 1.8 and 2.0), a sample was run on a $1 \%$ TAE agarose gel to check for RNA degradation. RNA integrity was noted by observation of two sharp and discrete $26 \mathrm{~S}$ and $18 \mathrm{~S}$ ribosomal bands and the absence of leading smears, genomic DNA, and extra bands in each well. DNA-free RNA $(2 \mu \mathrm{g}$ in a total volume of $40 \mu \mathrm{l}$ ) was then converted to complementary DNA using oligo (dT) primers and a two-step RT-PCR procedure with heat denaturation (RETROscript Kit, Ambion \#AM1710) according to the manufacturer's instructions.

Quantitative real-time PGR and qPGR primers. Amplification reactions were carried out in a total volume of $20 \mu \mathrm{l}$ containing the SYBR Premix Ex Taq reagent (Clontech Laboratories, Inc., Takara Product \#TAK RR041A), $0.3 \mu \mathrm{M}$ of gene-specific forward and reverse primers, and cDNA corresponding to $100 \mathrm{ng}$ input RNA in the reverse transcriptase reaction. The reaction conditions for the Opticon 2 system (MJ Research) were: $95^{\circ} \mathrm{C}$ for $5 \mathrm{~min}$, followed by 40 cycles of $95^{\circ} \mathrm{C}$ for $10 \mathrm{~s}, 60^{\circ} \mathrm{C}$ for $20 \mathrm{~s}, 72^{\circ} \mathrm{C}$ for $20 \mathrm{~s}$. The fluorescence was measured at each cycle at $80^{\circ} \mathrm{C}$. Melting curves were performed after the PCR to assess the presence of a unique final product, and for each primer pair the product from one reaction was run on an agarose gel to further verify specificity and to confirm the expected band size.

The gene expression data are presented as the -fold change in mRNA transcript abundance in transgenic or mutant worm strains, normalized to two endogenous reference genes $(c d c-42$ and ama-1), relative to the wild-type $\mathrm{N} 2$ strain. $C d c-42$ encodes the RHO GTPase and ama-1 encodes RNA polymerase II; both genes were previously validated as relatively reliable reference genes to use for quantitative gene expression studies in C. elegans [33]. The expression results were similar when normalized against $c d c-42$ or ama-1 individually. Normalized -fold changes (and statistical significance) were calculated using the REST 2009 software (Qiagen).

Quantitative real-time PCR primers were newly designed for the $C$. elegans genes ama-1 (forward primer: 5'-CGGTCAGAAAGGCTATCGAG-3'; reverse primer: 5'-CGAACCTCGTGACGATTGAT-3'), pcm-1 (forward primer: 5'-TGTATGGCAATGATGGTTGG-3'; reverse primer: 5'-ACGACCGTCTCGCTCAATAA-3'), and $h s p-12.6$ (forward primer: 5'-GTGATGGCTGACGAAGGAAC-3'; reverse primer: 5'-GGGAGGAAGTTATGGGCTTC-3'). Previously published primer pairs were used for the C. elegans genes $c d c-42$ [33], sod-3, daf-16 [34], mtl-1, dod-3, F21F3.3, dod-22, and dod-24 [35].

\section{Quantification of protein substrates for the L-isoaspartyl methyltransferase in $C$. elegans extracts}

Nematodes from each strain (N2, PL51, and pcm-1 (qa201)) were grown at either $20^{\circ} \mathrm{C}$ or $25^{\circ} \mathrm{C}$ for 5 days in liquid cultures 
(S-media supplemented with concentrated E. coli OP50) and harvested by washes and sucrose flotation as previously described [24]. Preparation of C. elegans cytosol and determination of protein concentration therein was also done as previously [24]. To quantify the level of isoaspartyl methyltransferase substrates in the various protein extracts, base-labile methyl ester groups were assayed in those extracts by a method modified from that of Kagan et al. [24]. Specifically, nematode cytosolic extracts $(125 \mu \mathrm{g}$ protein) were incubated in a $50 \mu \mathrm{l}$ reaction mixture of the following composition: 0.1 M Bis-Tris ( $\mathrm{pH}$ 6.4) buffer, $0.67 \mu \mathrm{M} S$-adenosyl$L$ - $\left[\right.$ methyl $\left.{ }^{3} \mathrm{H}\right]$ methionine (Perkin Elmer, $78 \mathrm{Ci} / \mathrm{mmol}$ ), and $2.9 \mu \mathrm{g}$ human recombinant L-isoaspartyl methyltransferase (this enzyme preparation had a specific activity of $19.5 \mathrm{nmol} \mathrm{min}{ }^{-1} \mathrm{mg}^{-1}$ when the peptide KASA-isoD-LAKY was used as a substrate). The reaction mixtures were incubated for $2 \mathrm{~h}$ at $30^{\circ} \mathrm{C}$ and were quenched via addition of $50 \mu \mathrm{l} 2 \mathrm{X}$ Laemmli sample buffer containing $10 \% \beta$-mercaptoethanol followed by heating at $70^{\circ} \mathrm{C}$ for $8 \mathrm{~min}$. Approximately $40 \mu \mathrm{g}$ of the polypeptides within the above reaction mixtures were then separated by gel electrophoresis using NuPAGE ${ }^{\circledR}$ Novex 4-12\% SDS-PAGE gels $(\mathrm{pH}=7)$ (Catalog \# NP0335) and NuPAGE ${ }^{\circledR}$ MES SDS Running Buffer (Catalog \#NP002) from Invitrogen. The level of base-labile $\left[{ }^{3} \mathrm{H}\right]-$ methyl esters was assayed in $3 \mathrm{~mm}$ gel slices by a vapor diffusion method as described by Kagan $e t$ al. [24], except that $150 \mu \mathrm{l}$ of $1 \mathrm{~N}$ sodium hydroxide were added to the gel slices and that scintillation vials were incubated at $38^{\circ} \mathrm{C}$ for 24 hours before counting. Methyl-accepting proteins were quantified in two or three biological replicate extracts for each worm strain tested.

\section{Results}

\section{PCM-1 overexpression extends lifespan in a \\ DAF-16-dependent manner}

It has previously been shown that PCM-1 overexpression extends the lifespan of adult nematodes under mild thermal stress [17]. Nematodes expressing a PCM-1 protein with a mutated AdoMet-binding site in a pcm-1 null background (PL54 strain) had a lifespan that was similar to wild-type (N2) animals under the same conditions indicating that the lifespan extension of the overexpressor (PL51) strain was dependent on the methyltransferase activity of PCM-1 [17]. We confirm here that the lifespan extension observed in the PL51 strain is dependent on PCM-1 overexpression, as the lifespan of PL51 adult nematodes fed with two different clones of $p c m-1$ RNAi was comparable to that of wildtype nematodes treated with control RNAi (Figure S1). The lifespan of wild-type nematodes was not significantly affected by pcm-1 RNAi.

To test whether the PCM-1 overexpression effect was due to a modulation of the IIS system, we tested the dependence of this effect on the presence of DAF-16, the critical downstream transcription factor of the IIS. Specifically, we grew the N2, PL51, and PL54 strains on bacteria expressing scrambled control RNAi or daf-16 RNAi and used FUDR to prevent egg laying and cross generation sampling $[29,36]$. We confirmed that PCM-1 overexpressing animals display on average an increase of $38 \%$ and $51 \%$ in median and maximum lifespan, respectively, compared to wildtype animals, and that no change in survival is observed between wild-type animals and nematodes expressing a catalytically inactive PGM-1 enzyme (Fig. 1, Table 2). In all strains tested, the lifespan values obtained in this study in the presence of FUDR were slightly reduced compared to those obtained previously in the absence of FUDR by Banfield et al. [17], but the same lifespan patterns were observed on control RNAi bacteria (Fig. 1, Table 2). All lifespan extensions (including the $50 \%, 25 \%$ and $10 \%$ survival
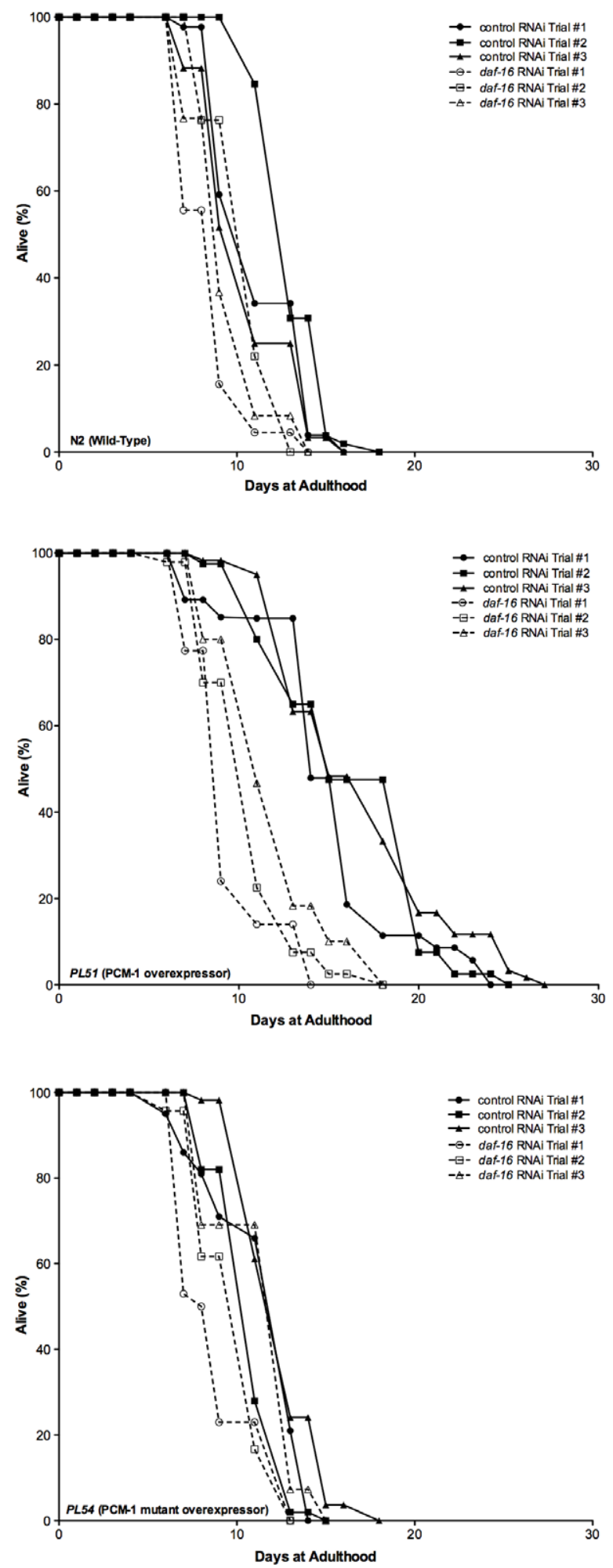

Figure 1. PCM-1 overexpression extends lifespan in a daf-16dependent manner under mild thermal stress $\left(25^{\circ} \mathrm{C}\right)$. Lifespan analyses (three trials) were completed at $25^{\circ} \mathrm{C}$ for three nematode strains (N2 wild-type (top panel), wild-type PCM-1 overexpressor strain (PL51) (middle panel), mutant PCM-1 overexpressor strain (PL54) (bottom panel)) grown in two conditions: control RNAi (solid lines) and daf-16 RNAi (dotted lines). L4 larvae were transferred (Day 0) to NGM plates streaked with RNAi bacteria and survival was scored every other day until all nematodes were dead. Statistical analysis of these data is given in Table 2 . doi:10.1371/journal.pone.0020850.g001 
Table 2. PCM-1 overexpression extends $C$. elegans lifespan in a DAF-16-dependent manner under mild thermal stress $\left(25^{\circ} \mathrm{C}\right)$.

\begin{tabular}{llllll}
\hline Strain & $\mathbf{n}$ & $\mathbf{5 0 \%}$ Survival (Hours) & $\mathbf{2 5 \%}$ Survival (Hours) & $\mathbf{1 0 \%}$ Survival (Hours) & Maximum Lifespan (Hours) \\
\hline N2 & 152 & $2.3 \pm 0.9$ & $3.2 \pm 0.8$ & $4.2 \pm 1.1$ & $5.0 \pm 0.8$ \\
$p C m-1$ (qa201) & 136 & $1.7 \pm 0.6(p=0.04)^{* *}$ & $2.8 \pm 0.6(p=0.003)^{* *}$ & $3.3 \pm 1.0(p=0.01)^{* *}$ & $4.0 \pm 1.0$ \\
$P L 51$ & 142 & $3.7 \pm 0.6$ & $4.5 \pm 0.5(p=0.04)^{*}$ & $5.2 \pm 0.6$ & $6.0 \pm 0.8$ \\
$P L 54$ & 123 & $2.7 \pm 1.0$ & $3.3 \pm 1.1$ & $3.9 \pm 1.2$ & $4.7 \pm 1.2$ \\
\hline
\end{tabular}

survival from the data in Figure 1 was determined using the one-way ANOVA test. One asterisk (*), significance compared to N2 control RNAi) and two asterisks $(* *$, significance compared to PL51 control RNAi) denote statistical significance at the indicated p-value. The total number of adult nematodes $(\mathrm{n})$ scored for survival in three replicates is indicated. Values represent the day ( \pm standard deviation) at which specified survival for each strain was observed.

doi:10.1371/journal.pone.0020850.t002

values) measured for the overexpressor strain were statistically significant when compared to wild-type (N2) animals (Table 2).

We found that methyltransferase-induced increase of survival was greatly limited by the RNAi knockdown of daf-16. Although small lifespan decreases were observed in wild-type and PL54 strains upon daf-16 RNAi feeding as compared to control RNAi, a much more pronounced reduction in survival was measured in the PL51 overexpressor strain in those conditions (Fig. 1 and Table 2). In the PL51 strain, median and maximum lifespan extensions over wild-type values were reduced from $38 \%$ and $51 \%$ on control RNAi to only 10 and $22 \%$ on daf-16 RNAi. These results show that the lifespan extension observed in PGM-1 overexpressing animals is at least partially dependent on daf-16 expression levels.

\section{PCM-1 overexpression enhances resistance to severe thermal stress}

In addition to displaying extended adult lifespans, daf-2 pathway mutants also show resistance to a variety of stressors, including severe thermal stress [32]. In testing the PL51 PCM-1 overexpressor strain for resistance to heat stress, we found that day 1 adults displayed increased thermotolerance at $37^{\circ} \mathrm{C}$ compared to wild-type (N2) animals, most significantly at the $25 \%$ survival time point (Fig. 2, Table 3). PL51 adult animals displayed 25\% survival at $4.5 \pm 0.5 \mathrm{~h}$ compared to $3.2 \pm 0.8 \mathrm{~h}$ in $\mathrm{N} 2$ animals. The enhanced thermotolerance appeared to be at least partially dependent on a functional methyltransferase cofactor-binding domain, as the PL54 animals did not show significantly increased survival at any noted time point. Furthermore, pcm-1 mutant animals displayed a significant decrease in thermotolerance when compared to PL51 animals at all $50 \%, 25 \%$, and $10 \%$ survival time points (Table 3).

Preliminary experiments using daf-16 RNAi indicates that the increased resistance to acute thermal stress of the PL51 overexpressor strain is, unlike the lifespan extension at $25^{\circ} \mathrm{C}, \mathrm{DAF}-16$ independent (Figure S2). To investigate this DAF-16 dependency under thermal stress further, we examined the effect of PCM-1 deficiency on the subcellular localization of this transcription factor at $25^{\circ} \mathrm{C}$ and $37^{\circ} \mathrm{C}$. 77356 nematodes (which express a GFPtagged DAF-16 protein) were fed bacteria expressing scrambled control RNAi or pcm-1 RNAi. Following incubation at $25^{\circ} \mathrm{C}$ for 48 hours or at $37^{\circ} \mathrm{C}$ for two hours, the cellular localization of DAF-16 was observed (Figure S3). In our experiments at $25^{\circ} \mathrm{C}$, DAF-16::GFP gave a diffuse signal indicating its presence in the cytosol as well as in the nucleus, concurring with results shown recently by Kawli and colleagues (37). No difference in DAF-16 subcellular localization was observed between control RNAi- or pcm-1 RNAi-fed animals. This is in agreement with the absence of a lifespan phenotype of the $p c m-1$ mutant at $25^{\circ} \mathrm{C}$. On control RNAi at $37^{\circ} \mathrm{C}$, DAF- 16 expression was mostly nuclear, confirming previous studies [28] (Figure S3). A similar nuclear localization was observed for DAF-16 on pcm- 1 RNAi after incubation at $37^{\circ} \mathrm{C}$ (Figure S3). Thus, PCM-1 deficiency does not affect DAF-16 localization under thermal stress. This indicates that the decreased resistance of the $p c m-1$ mutant to acute thermal stress that we observe here is not mediated by DAF-16. Further work will be needed to determine whether PCM-1 overexpression, unlike PCM-1 deficiency, affects DAF-16 localization.

\section{PCM-1 overexpression activates DAF-16-dependent gene expression}

Since the results from our lifespan analyses under mild thermal stress showed that the extended lifespan in PCM-1 overexpressing animals is dependent on daf-16 expression, we next wanted to determine whether PGM-1 overexpression modulates transcription of DAF-16 target genes previously linked to nematode longevity. cDNA was synthesized from total RNA extracted from synchronized day 1 adults (grown at $25^{\circ} \mathrm{C}$ ) and was used to measure expression levels of $p c m-1, d a f-16$, five genes previously shown to be up-regulated by DAF-16 (sod-3, hsp-12.6, dod-3, F21F3.3, and mtl-1) [35,38], and two genes previously shown to be downregulated by DAF-16 (dod-22 and dod-24) [35,38] by real-time

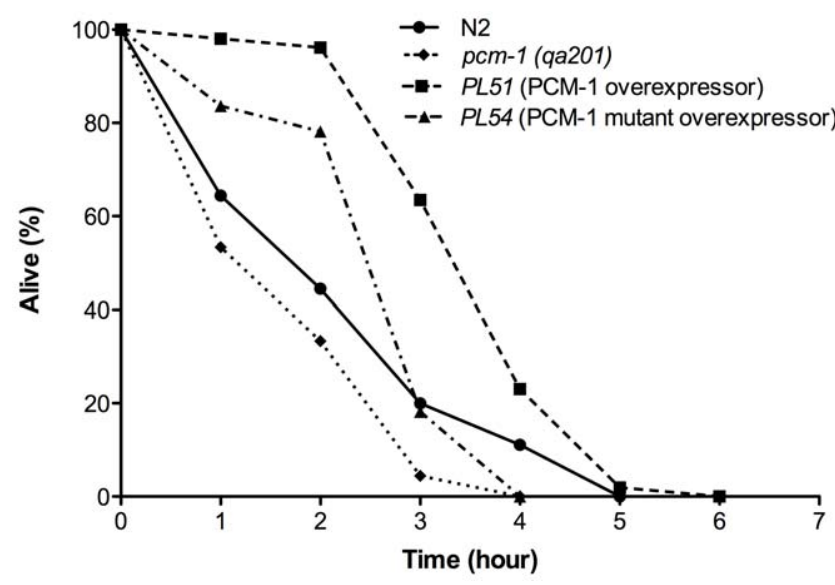

Figure 2. PCM-1 overexpression enhances resistance to severe heat stress $\left(37^{\circ} \mathrm{C}\right)$. Survival assays (three trials) were completed for four nematode strains (N2 wild-type, pcm-1 mutant (qa201), PCM-1 overexpressor strain (PL51), mutant PCM-1 overexpressor strain (PL54)). Shown are representative survival curves from one trial. L4 larvae were transferred to NGM + OP50 plates and were allowed to grow at $20^{\circ} \mathrm{C}$ overnight. The next day, animals were transferred to $37^{\circ} \mathrm{C}$ and survival was scored every two hours for the first four hours and every hour afterwards until all nematodes were dead. Statistical analysis of these data is given in Table 3 for the three replicates of this experiment. doi:10.1371/journal.pone.0020850.g002 
Table 3. PCM-1 overexpression enhances resistance to severe thermal stress $\left(37^{\circ} \mathrm{C}\right)$ in $\mathrm{C}$. elegans.

\begin{tabular}{llllll}
\hline Strain & $\mathbf{n}$ & $\mathbf{5 0 \%}$ Survival (Hours) & $\mathbf{2 5 \%}$ Survival (Hours) & $\mathbf{1 0 \%}$ Survival (Hours) & Maximum Lifespan (Hours) \\
\hline N2 & 152 & $2.3 \pm 0.9$ & $3.2 \pm 0.8$ & $4.2 \pm 1.1$ & $5.0 \pm 0.8$ \\
$p c m-1$ (qa201) & 136 & $1.7 \pm 0.6(p=0.04)^{* *}$ & $2.8 \pm 0.6(p=0.003)^{* *}$ & $3.3 \pm 1.0(p=0.01)^{* *}$ & $4.0 \pm 1.0$ \\
$P L 51$ & 142 & $3.7 \pm 0.6$ & $4.5 \pm 0.5(p=0.04)^{*}$ & $5.2 \pm 0.6$ & $6.0 \pm 0.8$ \\
$P L 54$ & 123 & $2.7 \pm 1.0$ & $3.3 \pm 1.1$ & $3.9 \pm 1.2$ & $4.7 \pm 1.2$ \\
\hline
\end{tabular}

Significance of survival from the data in Figure 2 was determined using a one-way ANOVA test. One asterisk (*, significance compared to N2) and two asterisks (**, significance compared to PL51) denote statistical significance at the indicated $p$-value. The total number of adult nematodes (n) scored for survival in four replicates is indicated. Values represent the hour ( \pm standard deviation) at which specified survival for each strain was observed.

doi:10.1371/journal.pone.0020850.t003

qPCR. Transcript levels for these experimental genes were normalized to the transcript levels of two reference genes $(c d c-42$ and $a m a-1)$ in all of the cDNA samples included in the study. Cdc42 and ama-1 were previously shown to be relatively stably expressed in various larval stages and daf-2 pathway mutants [33] and those genes can thus be considered as reliable reference genes for expression studies in the context of insulin-like signaling in C. elegans.

As expected, $p c m-1$ transcript levels in the overexpressor strain PL51 were significantly higher than in the wild-type strain (30-fold increase versus wild-type; Fig. 3A). Pcm-1 transcript levels were reduced by about 500 -fold versus wild-type in the $p \mathrm{~cm}-1$ deletion strain qa201 (Fig. 3A, Table 4). Surprisingly, in the mutant overexpressor strain PL54, pcm-1 transcript levels were not increased above wild-type levels as in the PL51 strain. However, PGR amplification of exon 3 (i.e. the region which contains the two point mutations that decrease AdoMet binding) from PL54 cDNA and subsequent sequencing confirmed that this strain expresses a $p c m-1$ transcript encoding the expected mutant methyltransferase. The reason for the low expression levels of this mutated transcript as compared to the non-mutated one in the PL51 strain remains presently unclear. It can be noted here that the plasmids used for creating the transgenic PL51 and PL54 strains (in a pcm-1 mutant background) also contained the C1OF3.4/mcp-1 gene, which overlaps the $p c m-1$ gene in the $C$. elegans genome in antiparallel orientation $[17,26]$. We found that the C1OF3.4/mcp-1 gene is overexpressed to similar extents in both the PL51 and PL54 strains (data not shown). This indicates that the difference in $p c m-1$ transcript levels between the two strains results from an effect of the mutations present in the $p c m-1$ transgene in the PL54 strain (but not the PL51 strain), rather than from a large difference in copy number of transgene DNA in the extrachromosomal array present in the two strains. Despite lower pcm-1 transcript levels compared to the PL51 strain, the PL54 strain thus remains an important control strain to exclude that phenotypes observed in the PL51 strain are due to C10F3.4/mcp-1 overexpression. The latter gene encodes for a GDPD-glucose phosphorylase that has been proposed to function in sanitizing the nucleotide sugar pool [39]. No significant changes in daf-16 transcript levels were observed in any of the transgenic or mutant strains compared to wild-type levels (Fig. 3A, Table 4).

The changes in transcript levels measured for DAF-16 target genes correlated with PCM-1 activity levels. Among the "DAF-16 up-regulated" genes, all five genes tested were up-regulated (4- to 20-fold increases vs. wild-type) in PCM-1 overexpressing animals, the increase being statistically significant for sod-3, hsp-12.6, and dod-3 (Fig. 3B, Table 4). Much less pronounced increases in transcript level versus wild-type level were observed for these "DAF-16 up-regulated" genes in the mutant overexpressor PL54 strain, except for the $h s p-12.6$ gene, for which similar increases were observed for the PL51 and PL54 strains. None of the five "DAF-16 up-regulated" genes was significantly up-regulated versus wild-type in the mutant $p \mathrm{~cm}-1$ strain and two of those genes (F21F3.3 and $m t l-1)$ were actually significantly downregulated in this strain (Fig. 3B, Table 4). As for the two "DAF16 down-regulated" genes tested, a down-regulation was also observed in the long-lived PCM-1 overexpressor for both the dod22 and dod-24 genes (about 2-fold decrease versus wild-type for both genes, Fig. 3C, Table 4). On the opposite hand, increases rather than decreases in expression were measured for those genes in the mutant overexpressor PL54 strain. In the mutant pcm-1 strain, dod-22 and dod-24 expression was down-regulated and upregulated versus wild-type, respectively (Fig. 3C, Table 4). We should note that the regulation of the mRNA levels of the genes examined here may involve transcription factors in addition to DAF-16; changes in the expression of pcm-1 may also affect daf-16independent pathways.

\section{PCM-1 overexpression may not lead to decreased protein damage in C. elegans}

Accumulation of damaged (isoaspartyl-containing) proteins has been clearly demonstrated over a wide range of molecular weights and in various tissues for isoaspartyl methyltransferase-deficient mice [12]. To better characterize the protein repair function of PCM-1 in C. elegans, we quantified the level of substrate proteins for the L-isoaspartyl methyltransferase in extracts prepared from wild-type, PL51, and pcm-1 (qa201) mutant strains. Therefore, we labeled worm protein extracts (prepared from liquid cultures containing a mixed larval and adult population grown for 5 days at $20^{\circ} \mathrm{C}$ ) with $\left[{ }^{3} \mathrm{H}\right]$ AdoMet and recombinant human isoaspartyl methyltransferase and then separated the polypeptides by SDS polyacrylamide gel electrophoresis at $\mathrm{pH} 7$ for analysis of $\left[{ }^{3} \mathrm{H}\right]$ methyl ester-containing proteins in individual gel slices as described in the Methods section.

In three independent experiments, we found significantly higher levels of base-labile $\left[{ }^{3} \mathrm{H}\right]$-methyl ester groups in pcm-1 (qa201) mutant extracts compared to wild-type extracts prepared from nematodes grown at $20^{\circ} \mathrm{C}$ (Figs. 4 and S4) for proteins of molecular weights ranging from about 25 to $200 \mathrm{kDa}$. However, for reasons that presently remain unclear, in two other experiments of the same type we did not observe as significant of an increase in protein damage in the $p \mathrm{~cm}-1$ mutant (Figure S5, top panel). For the two assays performed on extracts derived from nematodes grown at $25^{\circ} \mathrm{C}$, we did not observe significantly higher isoaspartyl levels in pcm-1 mutant protein extracts than in wildtype extracts (Figure S5, bottom panel). Further work is necessary to understand the reason underlying the variability of these results, but they indicate that $p c m-1$ mutant animals display a tendency to accumulate higher protein isoaspartyl levels. As pcm-1 mutant 


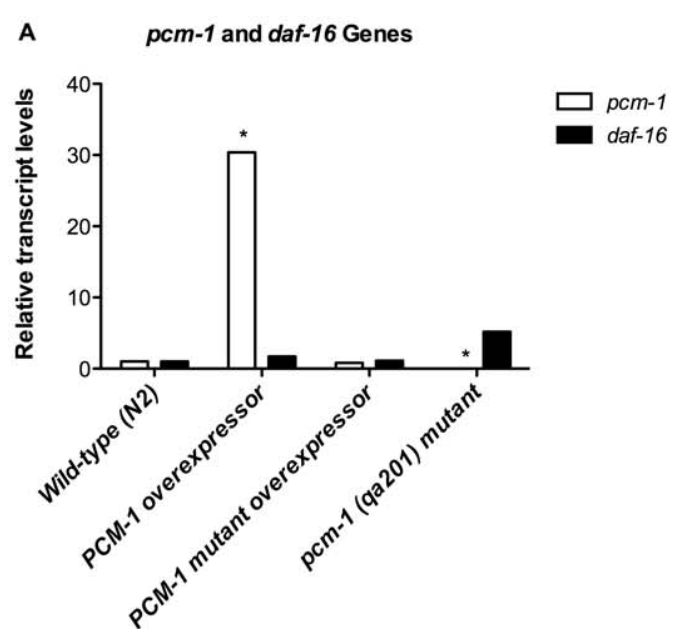

B daf-16 Up-regulated Genes

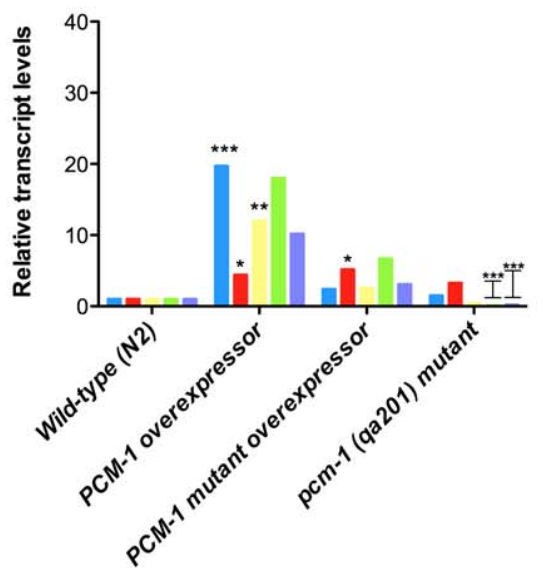

C daf-16 Down-regulated Genes

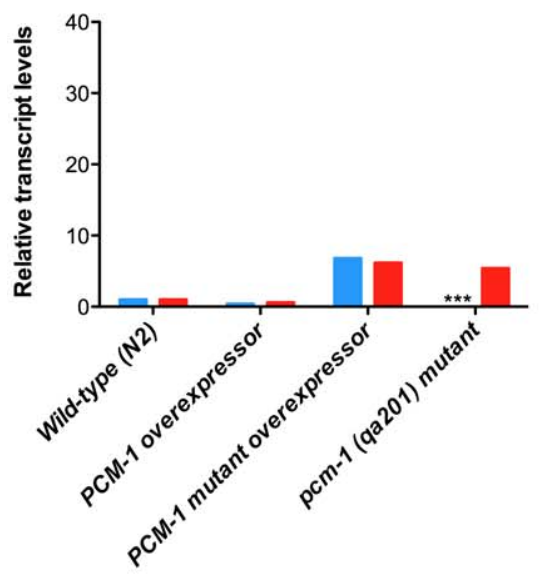

Figure 3. PCM-1 modulates expression levels of DAF-16 target genes at $25^{\circ} \mathrm{C}$. Fold changes for the expression of various genes in nematode strains PL51 (PCM-1 overexpressor), PL54 (mutant PCM-1 overexpressor), and pcm-1 (qa201) mutant ( $\mathrm{cm}-1$ null) versus wild-type (N2) are shown. Total RNA was extracted from animals grown at $25^{\circ} \mathrm{C}$. Relative transcript levels versus $\mathrm{N} 2$ are shown for $p \mathrm{~cm}-1$ and daf- 16 genes (panel A), DAF-16 up-regulated genes (panel B), and DAF-16 downregulated genes (panel C). Ama-1 and cdc-42 were used as endogenous reference genes for normalization of the transcript levels of all of the genes involved in this expression study. Normalized -fold changes and statistical significance were determined using the Qiagen REST 2009 program $\left({ }^{*} p \leq 0.05,{ }^{* *} p \leq 0.001,{ }^{* * *} p \leq 0.0001\right)$ as shown in Table IV. doi:10.1371/journal.pone.0020850.g003
C. elegans do not present any lifespan phenotype at either $20^{\circ} \mathrm{C}$ or $25^{\circ} \mathrm{C}$, these results indicate that isoaspartyl damage might not affect lifespan in nematodes. In all of our labeling experiments we generally observed a major peak of radioactive methyl group incorporation at $21 \mathrm{kDa}$, but the level of this incorporation seemed to be independent of PCM-1 activity.

We also measured isoaspartyl levels in protein extracts derived from PCM-1 overexpressing nematodes at both $20^{\circ} \mathrm{C}$ or 25 . Our results showed no decrease in base-labile $\left[{ }^{3} \mathrm{H}\right]$-methyl ester groups below basal wild-type levels in the PCM-1 overexpressing (PL51) extracts derived from nematodes grown at either $20^{\circ} \mathrm{C}$ or $25^{\circ} \mathrm{C}$. On the contrary, equal or variably increased amounts of damaged proteins in PL51 animals versus wild-type animals were observed (data not shown). This indicates that a several-fold increase in isoaspartyl methyltransferase activity over wild-type activity levels does not decrease isoaspartyl levels below those accumulating in wild-type animals and suggests that the lifespan extension displayed by PCM-1 overexpressing animals does not result from a decrease in overall protein damage (in agreement with the above conclusion that increased protein damage does not affect lifespan).

\section{Discussion}

We show here that PCM-1 overexpression extends nematode lifespan under mild thermal stress $\left(25^{\circ} \mathrm{C}\right)$ in a DAF-16-dependent manner. This finding is in agreement with previous results indicating that PCM-1 activity in adult nematodes might be dispensable under control conditions, but becomes critically important under various stress conditions or in specific larval stages $[17,25,26]$. Similarly, in preliminary experiments carried out in preparation of this study, no lifespan extension over wild-type was observed in PCM-1 overexpressing nematodes when grown at $20^{\circ} \mathrm{C}$.

By employing daf-16 RNAi, we were able to show that a reduction in daf-16 expression partially reduced the lifespan extension displayed by the PL51 overexpressor strain at $25^{\circ} \mathrm{C}$. Daf- $16 \mathrm{RNAi}$ also decreased lifespan in the mutant overexpressor animals, but this reduction was much less pronounced and mimicked the one observed in wild-type animals. A small negative effect of daf-16 RNAi on lifespan in N2 animals has been reported previously $[40,41]$. Our results thus indicate that the PCM-1 isoaspartyl methyltransferase extends lifespan at $25^{\circ} \mathrm{C}$ at least partially by directly or indirectly downregulating the IIS pathway and thereby promoting nuclear translocation of DAF-16 with concomitant upregulation of target genes promoting survival under mild thermal stress (Figure 5).

The partial nature of the reduction of the PGM-1-dependent lifespan extension by daf-16 RNAi suggests that PCM- 1 might also act independently of daf-16 to increase lifespan. Possible targets include the transcription factor SKN-1 [42,43]. SKN-1 functions in parallel to DAF-16 to promote longevity and is also a direct target of IIS; in response to oxidative or xenobiotic stress, SKN-1 induces a set of stress response genes and reduced IIS leads to nuclear accumulation and transcriptional activation of SKN-1 in the intestine [42]. Alternatively, complete suppression of the lifespan extension may require daf-16 down-regulation also in the neurons. It has been shown that RNAi does not penetrate neurons effectively in C. elegans animals [44,45]; we have confirmed this result here by finding that daf-16 RNAi treatment does not affect DAF-16 expression in neurons. Although DAF-16 activation occurs in both neuronal and intestinal cells, it has been shown that DAF-16 activity specifically in the intestine increases the lifespan of daf-2;daf-16 double mutants substantially [46,47]. However, it has also been shown that lifespan extension in age-1 mutants requires both neuronal and intestinal DAF-16 activity $[47,48]$. 


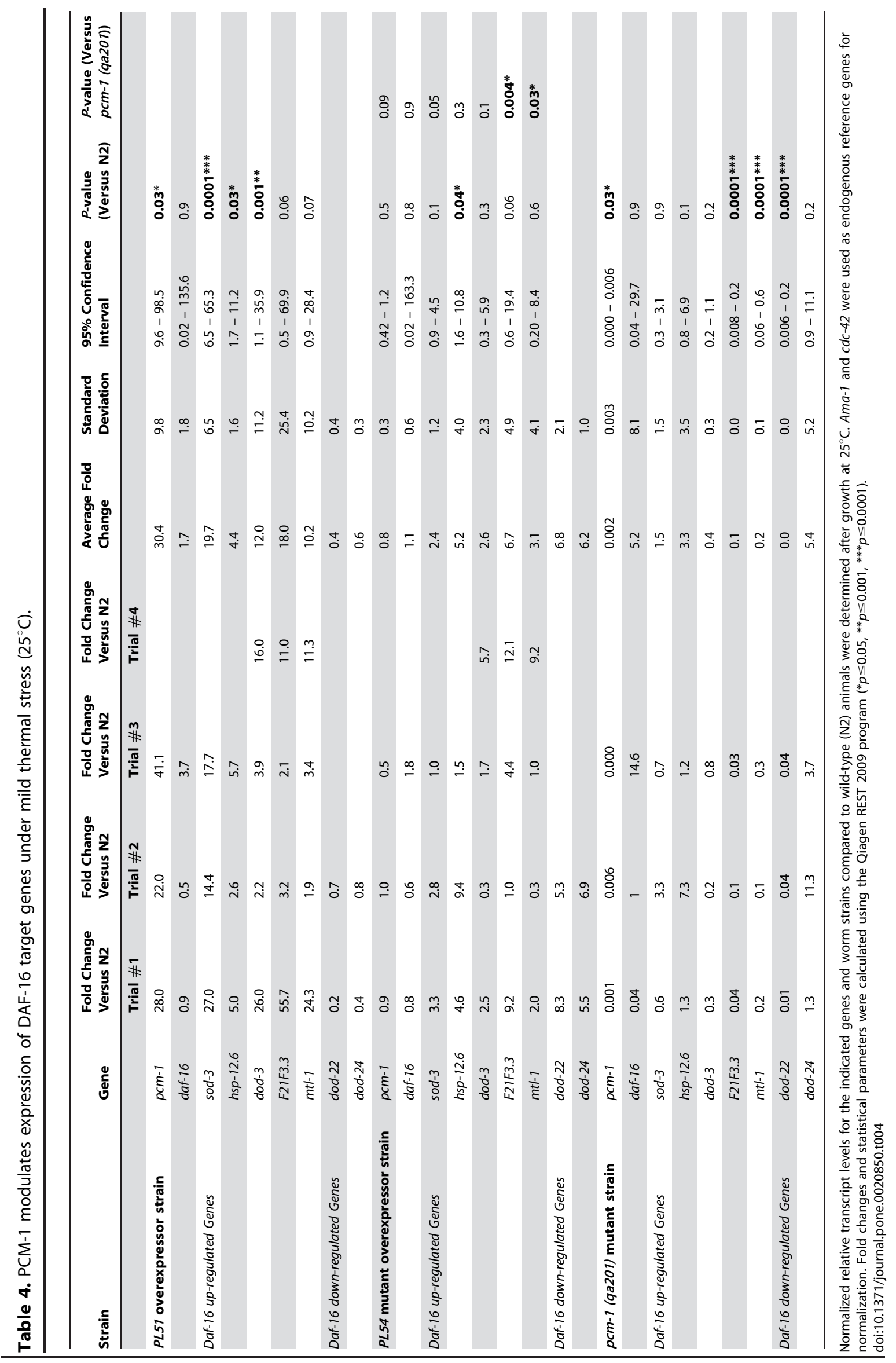




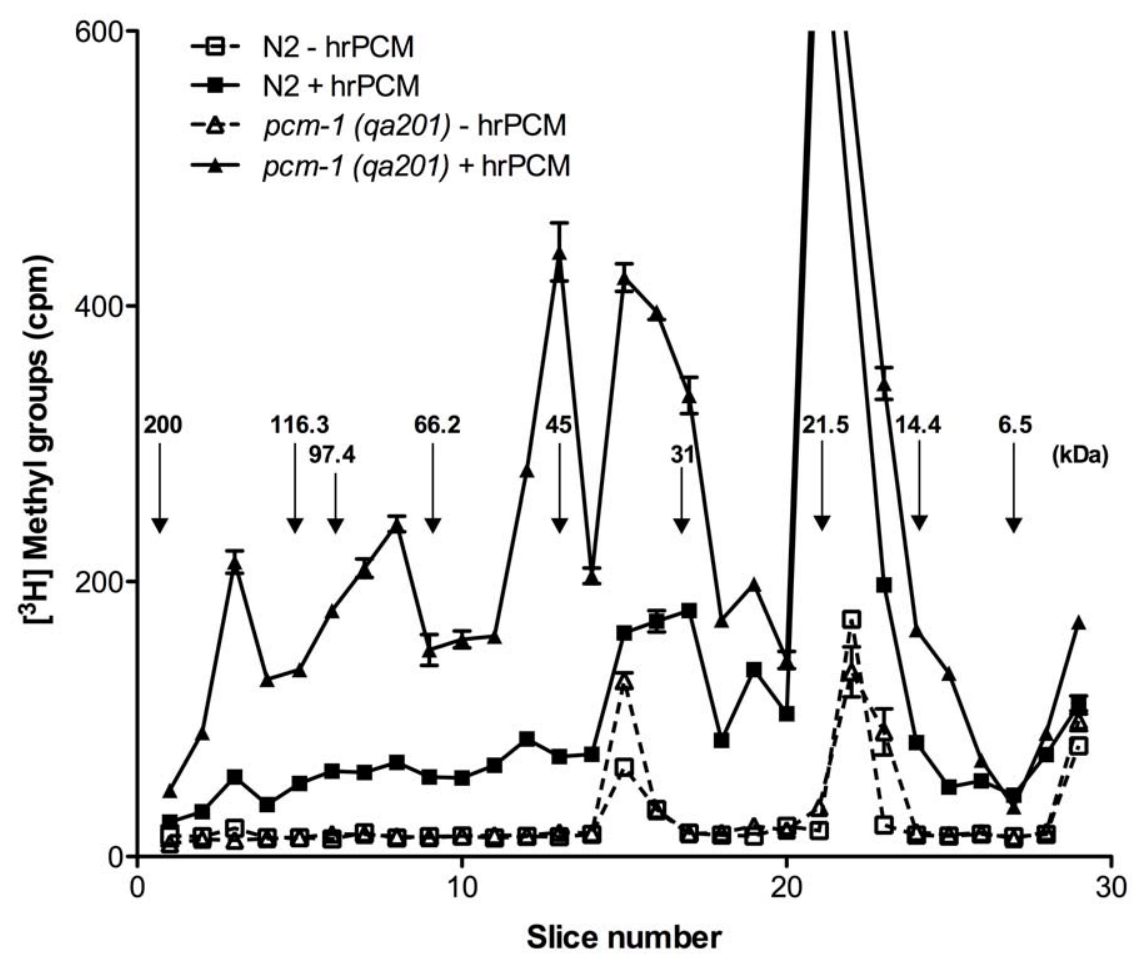

Figure 4. Quantification of methyl-accepting protein substrates in C. elegans extracts for the recombinant human L-isoaspartyl methyltransferase at $20^{\circ} \mathrm{C}$. Protein extracts from N2 and pcm-1 (qa201) nematode strains were prepared from a mixed stage nematode population after liquid culture for 5 days at $20^{\circ} \mathrm{C}$ and incubated with $\left[{ }^{3} \mathrm{H}\right]$ AdoMet and without or with recombinant human L-isoaspartyl methyltransferase as described in the Methods section. Base-labile methyl esters were quantified in wild-type (N2 - hrPCM, dashed line with open rectangles; N2 + hrPCM, solid line with closed rectangles) and pcm-1 (qa201) mutant (pcm-1 (qa201) - hrPCM, dashed line with open triangles; pcm-1 (qa201) + hrPCM, solid line with closed triangles) strains after polypeptide fractionation by SDS polyacrylamide gel electrophoresis. The migration positions of the molecular weight markers in $\mathrm{kDa}$ are indicated by arrows (Biorad SDS-PAGE Standards Catalog \#161-0317). Base-labile [3 $\mathrm{H}]-$ methyl ester groups present in peak 22 (not visible in figure) for N2 + hrPCM and pcm-1 (qa201) + hrPCM are 7285 cpm and 3683 cpm, respectively. Similar results were obtained in three independent experiments; one representative experiment is shown here and two others in Figure S4. doi:10.1371/journal.pone.0020850.g004

Thus, it is possible that the small lifespan extension we observe with PCM-1 overexpression in the daf-16 RNAi treated adult nematodes is a result of DAF-16 activation in neurons. It is also known that PCM-1 is expressed primarily in the neurons, body wall, and reproductive tissues in C. elegans [25]. We thus speculate that a complete suppression of the daf-16-dependent lifespan extension triggered by PCM-1 overexpression might only be achieved in neuronal RNAi-sensitive worm strains.

We also observed an increase in median survival under severe thermal stress $\left(37^{\circ} \mathrm{C}\right)$ in the overexpressor strain that is dependent on a functional L-isoaspartyl methyltransferase. Preliminary examination of the enhanced thermal stress resistance in the PL51 strain indicates that the increased thermotolerance observed is daf-16-independent (Figure S2). In agreement with this, our preliminary microscopy results show that $p c m-1$ RNAi does not suppress nuclear localization of DAF-16 during heat shock at $37^{\circ} \mathrm{C}$ (Figure S3). Thus, increased survival of the PL51 nematodes at $37^{\circ} \mathrm{C}$ might involve a DAF-16-independent mechanism.

Real-time qPGR analyses showed a PGM-1-dependent induction of the DAF-16 target genes sod-3, F21F3.3, mtl-1, and dod-3 at $25^{\circ} \mathrm{C}$. The 20 -fold induction of sod-3 transcription and the approximately 10-fold to 20-fold induction of the dod-3, F21F3.3, and $m t l-1$ genes over wild-type levels in the PCM-1 overexpressor strain at $25^{\circ} \mathrm{C}$ further solidifies our hypothesis of PCM-1 downregulating IIS signaling to extend nematode longevity under mild thermal stress. We note that $m t l-1$ expression can also be regulated by the ELT-2 transcription factor [49]. At this point, we cannot rule out effects of PCM-1 on DAF-16-independent pathways. Although the bulk of our evidence points to the linkage of PCM-1 activity to the activity of DAF-16, it is possible that PCM-1 can affect DAF-16 target genes through other transcription factors.

Surprisingly, the mutant overexpressor strain PL54 did not overexpress $p \mathrm{~cm}^{-1}$ to the same extent as the wild-type overexpressor strain PL51. We confirmed the presence of the expected point mutations in the pcm-1 transcript in the PL54 strain, and consequently believe that the mutant overexpressor strain expresses a non-functional PCM-1 protein at lower levels, as our activity assays confirm that there is no PCM-1 activity in this strain. It was interesting to observe that a few of the "DAF-16 up-regulated" genes were also significantly up-regulated compared to wild-type animals in the PL54 mutant overexpressor strain. Except for hsp12.6, for which an approximate 5-fold induction was observed in both PL54 and PL51 strains, the levels of induction of the other DAF-16 up-regulated genes were, however, much lower in the PL54 mutant overexpressor strain than those reached in the PL51 wildtype overexpressor strain. These effects may be attributed to the regulation of $h s p-12.6$ by the $\mathrm{HSF}-1$ transcription factor (50) or by effects of the $C 10 F 3.4 / m c p-1$ gene which overlaps the $p c m-1$ gene in antiparallel orientation and which is overexpressed to the same extent in both the PL51 and PL54 transgenic strains.

Concerning the "DAF-16 down-regulated" genes analyzed in our expression study (dod-22 and dod-24), the results obtained in the PCM-1 transgenic strains (about 2-fold down-regulation in the PL51 strain as opposed to an about 6- to 7-fold up-regulation in 


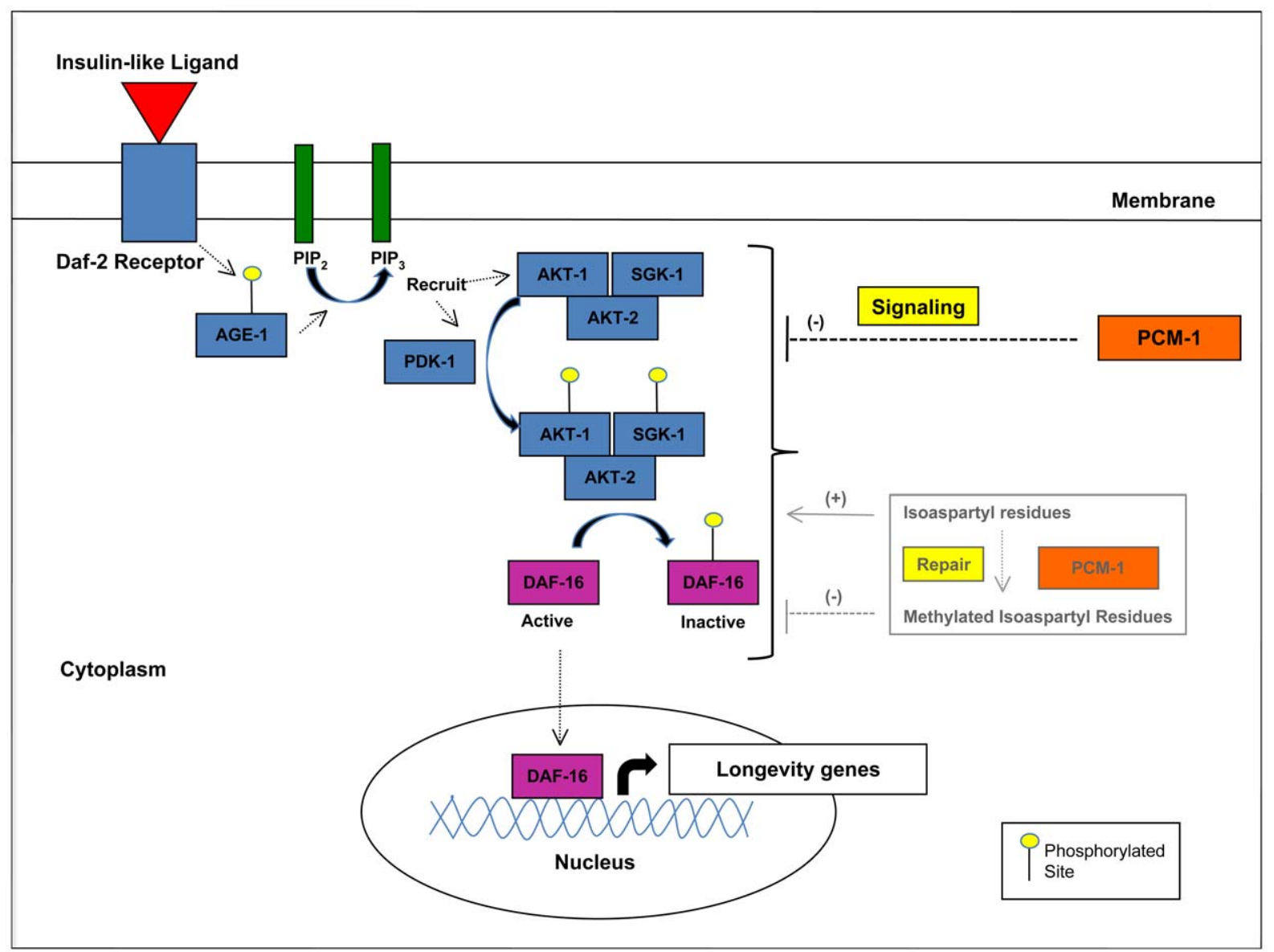

Figure 5. The protein L-isoaspartyl $O$-methyltransferase (PCM-1) opposes insulin-like signaling to extend $C$. elegans lifespan. Upon binding of the insulin-like ligand to the DAF-2 receptor, the AGE-1 kinase is activated and phosphorylates membrane-bound phosphatidylinositol-4,5bisphosphate $\left(\mathrm{PIP}_{2}\right)$, leading to the formation of phosphatidylinositiol-3,4,5-trisphosphate $\left(\mathrm{PIP}_{3}\right)$ and recruitment of kinases PDK-1 and AKT-1/AKT-2/ SGK-1 complex to the membrane. PDK-1 subsequently phosphorylates and activates the AKT/SGK complex, leading to further phosphorylation and inactivation of the FoxO transcription factor DAF-16. In the absence of phosphorylation, DAF-16 enters the nucleus to induce transcription of genes implicated in stress resistance and longevity. Our results indicate that overexpression of the protein repair enzyme PCM-1 leads to down-regulation of the insulin-like signaling pathway and subsequent activation of DAF-16, leading to increased transcription of longevity genes. Our results also show that, although absence of PCM-1 activity leads to increased accumulation of protein damage, its overexpression might not decrease the level of isoaspartyl-containing proteins beyond wild-type levels. This suggests that PCM-1 might control lifespan in C. elegans through a regulatory signaling function rather than through its role in bulk protein repair. doi:10.1371/journal.pone.0020850.g005

the PL54 strain) also support our hypothesis of a PCM-1 mediated downregulation of the IIS. However, whereas the $d_{0} d-24$ gene was up-regulated to a similar extent in the PL54 mutant overexpressor strain as in the $p c m-1$ deletion strain, a more puzzling result was the very low expression measured for $d o d-22$ in the latter strain. It might be noted here that the status of the $d o d-22$ and $d o d-24$ genes as "downstream of DAF-16" targets is presently controversial. Initial work by Murphy and colleagues [38] identified $d o d-22$ and dod-24 as genes acting downstream of DAF-16 to regulate longevity in $C$. elegans. These genes were also shown to be downregulated in long-lived TGF- $\beta$ mutant adult animals and this regulation was dependent on DAF-16 [51]. Additionally, the dod22 and dod-24 genes were used as control down-regulated DAF-16 target genes in a recent study on $\mathrm{HCF}-1$, a negative regulator of DAF-16 [35]. Other recent studies [52,53] suggest, however, that regulation of $d o d-22$ and $d o d-24$ expression is largely independent of DAF-16. Dod-24 expression was shown to be negatively regulated by the nuclear hormone receptor DAF-12 via signaling from the somatic reproductive tissues and independently of DAF-16 [48] and dod-22 expression has been shown to be regulated by the p38/MAPK pathway independently of DAF-16 [53]. Both studies show only a partial/restrictive dependence on DAF-16, explaining their presence in the original screen [38]. Given those recent observations on the regulation of $d o d-22$ and dod-24 expression, the effects of PCM-1 on the expression levels of those genes might not, or only be partially mediated by DAF-16. Further work is needed to clarify this point.

To determine whether an increase in PGM-1 activity leads to increased protein repair in C. elegans, we measured protein isoaspartyl levels in wild-type, $p c m-1$ mutant, and PL51 extracts by using human recombinant isoaspartyl methyltransferase. Our results show an increased isoaspartyl content in $\mathrm{pcm}^{-1}$ mutant extracts compared to wild-type extracts prepared from nematodes grown in liquid culture, suggesting a defect in the repair of isoaspartyl residues in the absence of methyltransferase. In the PCM-1 overexpressing (PL51) extracts, there was no apparent decrease in isoaspartyl damage compared to wild-type levels. However, PL51 is a non-integrated transgenic strain, with an observed transmission of about $30 \%$. Thus, we estimate that the liquid cultures from which we prepared our extracts contained 
about 30\% PCM-1 overexpressing transgenic animals and $70 \%$ non-transgenic pcm-1 mutant animals. Hence, if the transgenic PCM-1 overexpressing animals had decreased levels of isoaspartyl damage, this change may have been masked by the increased levels of damage in the $70 \%$ non-transgenic $p c m-1$ mutant nematodes.

Taken together, these results suggest that increased accumulation of protein damage (as observed in mutant $p c m-1$ animals) does not affect lifespan (no difference in lifespan between wild-type and pcm-1 mutant animals) and, conversely, that PCM-1 overexpression might not extend lifespan by decreasing the overall content of damaged proteins in the cell. Rather, PCM-1 may act as a signaling protein to directly or indirectly downregulate the IIS pathway to turn on expression of stress resistance genes via activation of DAF-16 (Figure 5). One possible mechanism could be a posttranslational regulatory carboxyl methylation of an intermediate of the IIS or of a protein phosphatase by PCM-1. The future identification of such potential regulatory targets of PCM-1 will help elucidate the mechanism of the observed interaction between the isoaspartyl methyltransferase, the IIS, and lifespan control in nematodes as well as in higher organisms.

\section{Supporting Information}

Figure S1 Pcm-1 RNAi reduces the lifespan extension of PGM-1 overexpressing adult nematodes at $25^{\circ} \mathrm{C}$. Lifespan analyses (one trial) were completed at $25^{\circ} \mathrm{C}$ (with FUDR) for two nematode strains (N2 wild-type (top panel) and wild-type PCM-1 overexpressor strain (PL51) (bottom panel)) grown in three conditions: control RNAi (solid lines) and pcm-1 RNAi (clones \#2 and \#3, dotted lines). L4 larvae were transferred (Day 0) to NGM plates streaked with RNAi bacteria and survival was scored every other day until all nematodes were dead. Wild-type (N2) animals scored for survival were as follows: control $(\mathrm{n}=74)$ and pcm-1 RNAi conditions ( $\mathrm{n}=77$ for pcm-1 RNAi clone \#2; $\mathrm{n}=76$ for pcm-1 RNAi clone \#3). PL51 animals scored for survival were as follows: control $(\mathrm{n}=55)$ and $p c m-1$ RNAi conditions $(\mathrm{n}=70$ for pcm-1 RNAi clone \#2; $\mathrm{n}=70$ for pcm-1 RNAi clone \#3). (TIF)

Figure S2 Daf-16 RNAi does not significantly affect resistance to severe heat stress $\left(37^{\circ} \mathrm{C}\right)$ in PCM-1overexpressing animals. Survival assays (one trial) were completed for two nematode strains (N2 wild-type and PCM-1 overexpressor strain (PL51)) in control RNAi and daf-16 RNAi conditions. L4 larvae were transferred to NGM + RNAi plates and were allowed to grow at $20^{\circ} \mathrm{C}$ overnight. The next day, animals were transferred to $37^{\circ} \mathrm{C}$ and survival was scored every two hours for the first four hours and every hour afterwards until all nematodes were dead. Wild-type (N2) animals scored for survival were as follows: control $(\mathrm{n}=27)$ and daf-16 RNAi conditions $(\mathrm{n}=26)$. PL51 animals scored for survival were as follows: control $(\mathrm{n}=15)$ and daf-16 RNAi conditions $(\mathrm{n}=20)$.

(TIF)

Figure S3 Monitoring DAF-16 localization with pcm-1 RNAi under mild $\left(25^{\circ} \mathrm{C}\right)$ and severe $\left(37^{\circ} \mathrm{G}\right)$ thermal stress. 17356 nematode animals were fed bacteria expressing either control (scramble) or pcm-1 RNAi as described in the Methods sections. DAF-16 localization was monitored using Nomarski differential interference contrast microscopy at 200-fold

\section{References}

1. Engelman JA, Luo J, Cantley LC (2006) The evolution of phosphatidylinositol 3-kinases as regulators of growth and metabolism. Nature Reviews Genetics 7: 606-619. magnification. The top three panels show mostly diffuse, unlocalized DAF-16 expression in animals fed control RNAi $(\mathrm{n}=22), p c m-1$ RNAi clone \#2 $(\mathrm{n}=25)$, and pcm-1 RNAi clone \#3 $(\mathrm{n}=19)$ at $25^{\circ} \mathrm{C}$. The bottom three panels show nuclear DAF-16 expression in animals fed control RNAi $(\mathrm{n}=8)$, pcm-1 RNAi clone \#2 ( $\mathrm{n}=12)$, and pcm-1 RNAi clone \#3 $(\mathrm{n}=13)$ following incubation at $37^{\circ} \mathrm{C}$. (PDF)

Figure S4 Quantification of protein isoaspartyl levels in additional $\boldsymbol{C}$. elegans extracts at $20^{\circ} \mathrm{C}$. Protein extracts were prepared from liquid nematode cultures grown at $20^{\circ} \mathrm{C}$ and analyzed for isoaspartyl content as described in Figure 4. Data from two additional biological replicate lysates are shown in panel A (replicate 1) and panel B (replicate 2). For panel A, base-labile $\left[{ }^{3} \mathrm{H}\right]$-methyl ester groups present in peak 22 (not visible in figure) for N2+ hrPGM and pcm-1 (qa201) + hrPCM are 14,514 cpm and $12,862 \mathrm{cpm}$, respectively. For panel $\mathrm{C}$, base-labile $\left[{ }^{3} \mathrm{H}\right]$-methyl ester groups present in peak 26 (not visible in figure) for $\mathrm{N} 2+$ hrPCM and pcm-1 (qa201) + hrPCM are $247 \mathrm{cpm}$ and $380 \mathrm{cpm}$, respectively. A less active human recombinant PCM was used in replicate 2 compared to the hrPCM used in the experiments shown in Figure 4 and in panel $\mathrm{A}$ of this Figure, but the same increase in base-labile $\left[{ }^{3} \mathrm{H}\right]$-methyl ester groups in labeled $\mathrm{pcm}-1$ (qa201) mutant extracts was observed.

(TIF)

Figure S5 Quantification of protein isoaspartyl levels in additional $C$. elegans extracts prepared from nematodes grown at $20^{\circ} \mathrm{C}$ (top panel) and $25^{\circ} \mathrm{C}$ (bottom panel). Protein extracts were prepared from liquid nematode cultures and analyzed for isoaspartyl content as described in Figure 4. The averages of data from two additional biological replicate lysates (prepared from nematodes grown at $20^{\circ} \mathrm{C}$ ) are shown in the top panel. Base-labile $\left[{ }^{3} \mathrm{H}\right]$-methyl ester groups present in peak 23 (not visible in figure) for N2+ hrPCM and pcm-1 (qa201) + hrPCM are $7,851 \mathrm{cpm}$ and 19,384 cpm, respectively. In the bottom panel, data from two biological replicate lysates (prepared from nematodes grown at $25^{\circ} \mathrm{C}$ ) for both strains are shown. Base-labile $\left[{ }^{3} \mathrm{H}\right]$-methyl ester groups present in peak 24 (not visible in figure) for N2+ hrPCM and pcm-1 (qa201)+ hrPCM are 4,858 cpm and 8,017 cpm, respectively.

(TIF)

\section{Acknowledgments}

We are grateful to Dr. Brian Head, Dr. Qinfang Shen, and Dr. Alex van der Bliek from the UCLA Department of Biological Chemistry for generously providing Ahringer library RNAi strains, and strain 17356 for experimentation, and for use of dissection and confocal microscopes. Additionally, we would like to thank Dr. Sabeeha Merchant from the UCLA Department of Chemistry and Biochemistry, for use of the Opticon machine and software for quantitative RT-PCR analysis. Finally, we would like to thank these colleagues, as well as Dr. Jonathan Lowenson and Dr. Jonathan Wanagat, for their helpful advice, assistance with statistics and other scientific guidance throughout this study.

\section{Author Contributions}

Conceived and designed the experiments: SK CLL. Performed the experiments: SK CLL. Analyzed the data: SK CLL SGC. Wrote the paper: SK CLL SGC. 
4. Friedman DB, Johnson TE (1988) A mutation in the age-1 gene in Caenorhabditis elegans lengthens life and reduces hermaphrodite fertility. Genetics 118: 75-86.

5. Kenyon C, Chang J, Gensch E, Rudner A, Tabtiang R (1993) A C. elegans mutant that lives twice as long as wild type. Nature 366: 461-646.

6. Ayyadevara S, Alla R, Thaden JJ, Shmookler-Reis RJ (2008) Remarkable longevity and stress resistance of nematode PI3K-null mutants. Aging Cell 7: 13-22.

7. Dorman JB, Albinder B, Shroyer T, Kenyon C (1995) The age-1 and daf-2 genes function in a common pathway to control the lifespan of Caenorhabditis elegans. Genetics 141: 1399-1406.

8. Ogg S, Paradis S, Gottleib S, Patterson GI, Lee L, et al. (1997) The Fork head transcription factor DAF-16 transduces insulin-like metabolic and longevity signals in C. elegans. Nature 389: $994-999$.

9. Kagan RM, Clarke S (1995) Protein L-isoaspartyl methyltransferase from the nematode Caenorhabditis elegans: genomic structure and substrate specificity. Biochemistry 34: 10794-10806.

10. Clarke S (2003) Aging as a war between chemical and biochemical processes: protein methylation and the recognition of age-damaged proteins for repair. Ageing Res Rev 2: 263-285.

11. Visick JE, Cai H, Clarke S (1998) The L-isoaspartyl protein repair methyltransferase enhances survival of ageing Escherichia coli subjected to secondary environmental stress. J Bacteriol 180: 2623-2629.

12. Kim E, Lowenson JD, MacLaren DC, Clarke S, Young SG (1997) Deficiency of a protein-repair enzyme results in the accumulation of altered proteins, retardation of growth, and fatal seizures in mice. Proc Natl Acad Sci USA 94: 6132-6137.

13. Ogé L, Bourdais G, Bove J, Collet B, Godin B, et al. (2008) Protein repair Lisoaspartyl methyltransferase 1 is involved in both seed longevity and germination vigor in Arabidopsis. Plant Cell 20: 3022-3037.

14. Kindrachuk J, Parent J, Davies GF, Dinsmore M, Attah-Poku S, et al. (2003) Overexpression of L-isoaspartate O-methyltransferase in Escherichia coli increases heat shock survival by a mechanism independent of methyltransferase activity. J Biol Chem 278: 50880-50886.

15. Verma P, Singh A, Kaur H, Majee M (2010) Protein L-isoaspartyl methyltransferase1 (CaPIMT1) from chickpea mitigates oxidative stress-induced growth inhibition of Escherichia coli. Planta 231: 329-336.

16. Chavous DA, Jackson FR, O'Connor GM (2001) Extension of the Drosophila lifespan by overexpression of a protein repair methyltransferase. Proc Natl Acad Sci USA 98: 14814-14818.

17. Banfield KL, Gomez TA, Lee W, Clarke S, Larsen PL (2008) Protein-repair and hormone-signaling pathways specify dauer and adult longevity and dauer development in Caenorhabditis elegans. J Gerontol A Biol Sci Med Sci 63: 798-808.

18. Farrar C, Houser CR, Clarke S (2005) Activation of the PI3K/Akt signaling pathway and increased levels of insulin receptor in protein repair-deficient mice. Aging Gell 4: 1-12.

19. Kosugi S, Furuchi T, Katane M, Sekine M, Shirasawa T, et al. (2008) Suppression of protein L-isoaspartyl (D-aspartyl) methyltransferase results in hyperactivation of EGF-stimulated MEK-ERK. Biochem Biophys Res Commun 371: 22-27.

20. Furuchi T, Sakurako K, Katane M, Sekine M, Homma H (2010) The role of protein L-isoaspartyl/D-aspartyl $O$-methyltransferase (PIMT) in intracellular signal transduction. Chem Biodivers 7: 1337-1348.

21. Doyle H, Gee RJ, Mamula MJ (2003) A failure to repair self-proteins leads to T cell hyperproliferation and autoantibody production. J Immunol 171: 2840-2847.

22. Lamarre M, Desrosiers RR (2008) Up-regulation of protein L-isoaspartyl methyltransferase expression by lithium is mediated by glycogen synthase kinase3 inactivation and beta-catenin stabilization. Neuropharmacology 5: 669-676.

23. Cournoyer P, Desrosiers RR (2009) Valproic acid enhances protein L-isoaspartyl methyltransferase expression by stimulating extracellular signal-regulated kinase signaling pathway. Neuropharmacology 56: 839-848.

24. Kagan RM, Niewmierzycka A, Clarke SG (1997) Targeted gene disruption of the Caenorhabditis elegans L-isoaspartyl protein repair methyltransferase impairs survival of dauer stage nematodes. Archives of Biochemistry and Biophysics 348: 320-328.

25. Gomez TA, Banfield KL, Glarke SG (2008) The protein L-isoaspartyl-Omethyltransferase functions in the Caenorhabditis elegans stress response. Mech Ageing Dev 129: 752-758.

26. Khare S, Gomez TA, Linster CL, Clarke SG (2009) Defective responses to oxidative stress in protein l-isoaspartyl repair-deficient Caenorhabditis elegans. Mech Ageing Dev 130: 670-680.

27. Sulston JE, Hodgkin J (1988) Methods. In: Wood WS, ed. The Nematode Caenorhabditis elegans. Cold Spring Harbor: Cold Spring Harbor Laboratory. pp 587-606.
28. Henderson ST, Johnson TE (2001) Daf-16 integrates developmental and environmental inputs to mediate aging in the nematode Caenorhabditis elegans. Current Biology 11: 1975-1980.

29. Sutphin GL, Kaeberlein M (2009) Measuring Caenorhabditis elegans life span on solid media. J Vis Exp 27 pii: 1152. doi: 10.3791/1152.

30. Kamath RS, Fraser AG, Dong Y, Poulin G, Durbin R, et al. (2003) Systematic functional analysis of the Caenorhabditis elegans genome using RNAi. Nature 421: 231-237.

31. Rual JF, Geron J, Koreth J, Hao T, Nicot AS, et al. (2004) Toward improving Caenorhabditis elegans phenome mapping with an ORFeome-based RNAi library. Genome Res 14: 2162-2168.

32. Lithgow G, White TM, Melov S, Johnson TE (1995) Thermotolerance and extended life-span conferred by single-gene mutations and induced by thermal stress. Proc Natl Acad Sci USA 92: 7540-7544.

33. Hoogewijs D, Houthoofd K, Matthijssens F, Vandesompele J, Vanfleteren JR (2008) Selection and validation of a set of reliable reference genes for quantitative sod gene expression analysis in C. elegans. BMC Mol Biol 22: 9

34. Zhang L, Jie G, Zhang J, Zhao B (2009) Significant longevity-extending effects of EGCG on Caenorhabditis elegans under stress. Free Radic Biol Med 46: 414-21.

35. Li J, Ebata A, Dong Y, Rizki G, Iwata T, et al. (2008) Caenorhabditis elegans HCF1 functions in longevity maintenance as a DAF-16 regulator. PLOS Biol 6: e233.

36. Mitchell DH, Stiles JW, Santelli J, Sanadi DR (1979) Synchronous growth and aging in Caenorhabditis elegans in the presence of fluorodeoxyuridine. J Gerontol 34: $28-36$.

37. Kawli T, Wu C, Tan M (2010) Systemic and cell instrinsic roles of Gq $\alpha$ signaling in the regulation of innate immunity, oxidative stress, and longevity in Caenorhabditis elegans. PNAS 107: 13788-13793.

38. Murphy CT, McCarroll SA, Bargmann CI, Fraser A, Kamath RS, et al. (2003) Genes that act downstream of DAF-16 to influence the lifespan of Caenorhabditis elegans. Nature 424: 277-283.

39. Adler LN, Gomez TA, Clarke SG, Linster CL (2011) A novel GDP-D-glucose phosphorylase involved in quality control of the nucleoside diphosphate sugar pool in Caenorhabditis elegans and mammals. J Biol Chem 286: in press.

40. Oh SW, Mukhopadhyay A, Svrzikapa N, Jiang F, Davis RJ, et al. (2005) JNK regulates lifespan in Caenorhabditis elegans by modulating nuclear translocation of forkhead transcription factor/DAF-16. Proc Natl Acad Sci USA 102: 4494-4499.

41. Raices M, Maruyama H, Dillin A, Karlseder J (2005) Uncoupling of longevity and telomere length in C. elegans. PLOS Genet 1: e30.

42. Tullet JM, Hertweck M, An JH, Baker J, Hwang JY, et al. (2008) Direct inhibition of the longevity-promoting factor SKN-1 by insulin-like signaling in $C$. elegans. Cell 132: 1025-1038.

43. Wang J, Robida-Stubbs S, Tullet JM, Rual JF, Vidal M, et al. (2010) RNAi screening implicates SKN-1-dependent transcriptional response in stress resistance and longevity deriving from translational inhibition. PLoS Genetics 6: e1001048.

44. Kamath RS, Martinez-Campos M, Zipperlen P, Fraser AG, Ahringer J (2001) Effectiveness of specific RNA-mediated interference through ingested doublestranded RNA in Caenorhabditis elegans. Genome Biol 2, Available http:// genomebiology.com/2000/2/1/research/0002. Accessed 2000 December 20.

45. Timmons L, Court DL, Fire A (2001) Ingestion of bacterially expressed dsRNAs can produce specific and potent genetic interference in Caenorhabditis elegans. Gene 263: 103-112.

46. Libina N, Berman JR, Kenyon C (2003) Tissue-specific activities of C. elegans DAF-16 in the regulation of lifespan. Cell 115: 489-502.

47. Panowski SH, Dillin A (2009) Signals of youth: endocrine regulation of aging in Caenorhabditis elegans. Trends Endocrinol Metab 20: 259-264.

48. Iser WB, Gami MS, Wolkow CA (2007) Insulin signaling in Caenorhabditis elegans regulates both endocrine-like and cell-autonomous outputs. Dev Biol 303: $434-447$.

49. Moilanen LH, Fukushige T, Freedman JH (1999) Regulation of metallothionein gene transcription. Identification of upstream regulatory elements and transcription factors responsible for cell-specific expression of the metallothionein genes from Caenorhabditis elegans. J Biol Chem 274: 29655-29665.

50. Hsu AL, Murphy CT, Kenyon C (2003) Regulation of aging and age-related disease by DAF-16 and heat-shock factor. Science 300: 1142-1145.

51. Shaw WM, Luo S, Landis J, Ashraf J, Murphy CT (2007) The C. elegans TGFbeta dauer pathway regulates longevity via insulin signaling. Curr Biol 17: 1635-1645

52. Yamawaki TM, Berman JR, Suchanek-Kavipurapu M, McCormick M, Gaglia MM, et al. (2010) The somatic reproductive tissues of $C$. elegans promote longevity through steroid hormone signaling. PLOS Biol 8: e1000468.

53. Alper S, McElwee MK, Apfeld J, Lackford B, Freedman JH, et al. (2010) The Caenorhabditis elegans germ line regulated distinct signaling pathways to control lifespan and innate immunity. J Biol Chem 285: 1822-1828. 